\title{
The Effect of Annealing Process and Mold Variations to Failure Time of CuznCast Alloy by Dynamic Load
}

\author{
Nurhabibah Paramitha Eka Utami ${ }^{1 *}$, DiahKusumaPratiwi ${ }^{1}$, Jimmy D Nasution ${ }^{1}$ \\ ${ }^{1}$ Department of Mechanical Engineering, University of Sriwijaya, 30622, Indonesia \\ nhparamitha@ft.unsri.ac.id
}

\begin{abstract}
The main objective of this study is to determine the influence of mold casting variations and annealing process of $\mathrm{CuZn}$ cast alloy. The CuZn cast alloy was annealed at 400 $\mathrm{C}$ to 2 hours. Failure time measurement was conducted by using Torsee's Torsion Repeated and Bending Fatigue Machine with only one level of loading $3^{\circ}$. Microstructure analysis performed by using Optical microscope to analyze its correlation with hardness value of $\mathrm{CuZn}$ cast alloy. Fracture Phenomenon of fracture fatigue specimen was analyses by using SEM.The reduction in fatigue toughness accompanied by the increase in ductility in CuZn cast alloy after annealing treatment.The decrease in mechanical properties also shown by the reduction of hardness value confirmed by changes size of its dendrite arm spacing. The results of the investigation revealed. The results showed a significant influence of the annealing process and mold variations on the failure time and mechanical properties of CuZn cast alloy.
\end{abstract}

Key words: CuZn Cast Alloy, Annealing, Failure time

\section{INTRODUCTION}

The CuZn alloy, also known as brass, has been used extensively in various fields of technology in the past 50 years because of its superior properties such as excellent corrosion resistance in atmospheric environments, good formability, thermal conductivity, and electrical conductivity and good machine capability [1]. The demand for this metal is growing rapidly because the combination of unique properties and formability with various machining methods makes it one of the most versatile materials [2]. The melting point of this alloy is about $900^{\circ} \mathrm{C}$ to $940^{\circ} \mathrm{C}$ make this material relatively easy to form due to its flow characteristics [3]. Exploration the process of forming and composition of alloys has been conducted in recent years as an effort to improve the quality of materials in high temperature applications without significant changes in strength.

\subsection{Metal Casting Process}

Utilization of recycled materials is expected to meet the need for material. In addition, the recycling process is labeled as the most effective way of preserving the environment and reducing resource extraction and energy consumption [4]. The most commonly used recycling method is the metal casting technique. This process can be used in various types of shapes, sizes, quantities based on quality and established requirements [5]. Thease in the process and low costs consumptions are the advantages of the casting process which is very useful in efforts to increase productivity while reducing product cost efficiency.

The casting process is one of the easiest manufacturing techniques that have been known since 3600 years BC. Sand casting is a common method that is relatively inexpensive, versatile and can produce castings of various sizes and shapes ranging from simple to complex. Limitations of sand casting are susceptible to casting defects. Casting defects may not be eliminated but can be kept as low as possible [6]. Permanent mold casting uses metal molds that reusable make this method more environmentally friendly. The advantages of metal molds are good surface finish, excellent heat transfer properties resulting in fine grains. The disadvantage of casting mold casting is the substantial investment in mold preparation but it is profitable for mass scale production.

\subsection{Heat Treatment}

The process of heat treatment in the industrial world is a influential process in determining the physical and mechanical properties of metal. The heat treatment of $\mathrm{CuZn}$ alloys in industrial applications aims not only to modify the structure, compounds and the properties that surround them. The annealing process can decrease the hardness value and internal pressure of the product which makes this metal easy in machining [7]. The Changes in microstructure after the annealing process has been studied. Literature [8] shows that annealing treatment influences the uniformity of microstructure. The effect of annealing itself is the reduction in tensile strength, hardness and increased ductility due to the segregation between crystals in CuZn Cast Alloy. Failure phenomenon by the dynamic load is estimated to be the cause of failure in more than $50 \%$ of mechanical components. Failures incurred primarily by fatigue can occur suddenly without warning make it more dangerous than static failures.

The main objective of this study is to investigate the influence of annealing process on two selected parameters which are the heat treatment process at $400{ }^{\circ} \mathrm{C}$ in 2 hours and types of mold in CuZn cast alloy. All these aspects are confirmed by fatigue test in one loading condition, microstructure analysis, fractography analysis and hardness test. 
Nurhabibah Paramitha Eka Utami et al., International Journal of Emerging Trends in Engineering Research, 8(9), September 2020, 5688 - 5692

\section{Experimental Details}

\subsection{Preparation CuZn Cast Alloy}

$\mathrm{CuZn}$ cast alloy in this reseach is taken from waste metals. The casting process was conducted by using crucible graphite with coal briquettes in temperature $1000^{\circ} \mathrm{C}$. The casting mold are made by permanent mold mild steel and single-use waste silica sand mold. X-ray fluorescence (XRF) was conducted to identify element constituent within CuZn cast alloy. Chemical analysis results are shown in table 1 below.

Table 1:Main Chemical Composition of CuZn Cast Alloy

\begin{tabular}{ccccccccccc}
\hline $\mathrm{Al}$ & $\mathrm{Zn}$ & $\mathrm{Cu}$ & $\mathrm{Sn}$ & $\mathrm{Sb}$ & $\mathrm{Pb}$ & $\mathrm{Ni}$ & $\mathrm{Fe}$ & $\mathrm{Mn}$ & $\mathrm{Si}$ & $\mathrm{S}$ \\
\hline$[\%]$ & {$[\%]$} & {$[\%]$} & {$[\%]$} & {$[\%]$} & {$[\%]$} & {$[\%]$} & {$[\%]$} & {$[\%]$} & {$[\%]$} & {$[\%]$} \\
\hline 1.3 & 29. & 65. & 0.8 & 0.5 & 1.6 & \multirow{2}{*}{0.8} & 0.0 & 0.2 & 0.4 & 0.3 \\
4 & 16 & 15 & 1 & 2 & 8 & & 9 & 1 & 7 & 2 \\
\hline
\end{tabular}

Casting Products then cutted based on various types of standard tests that will be performed by using metal cutting grinders then refined by using sandpaper starting from grit $\# 80$ and going up gradually to grit \#2400 to ensure the specimen surface is completely smooth.

\subsection{Heat Treatment}

The heat treatment process was carried out on both types of cast products, that are by using metal molds and cast product made by sand molds at $400^{\circ} \mathrm{C}$ for 2 hours. The cooling process was carried out in the furnace until temperature in the furnace back to room temperature. The purpose of the heat treatment process are to analyze microstructure evolution phenomenon of grain refining mechanism and its effect to the change of mechanical properties CuZn cast alloy.

\subsection{Hardness Test}

Hardness test carried out by using Brinell Hardness Test (BHN) with JIS Z 2243 standard. The selection of the Brinell method was to minimize errors in data retrieval due to tracking in areas with porosity. Specimen surface smoothing was conducted by using multi grades sandpaper $\# 80$, \#100, \#120, \#200, \#240, \#800, \#1000 and \#1500. Hardness value (BHN) obtained by using Equation 1 below :

$B H N=\frac{P}{\frac{\pi D}{2}\left(D-\sqrt{\left.D^{2}-d^{2}\right)}\right.}(1)$

\subsection{Metalography Analysis}

Microstructure observations were carried out to see the effect of heat treatment and the different types of molds on $\mathrm{CuZn}$ alloys. The preparation process of microstructure specimens are cutting, mounting, polishing, etching with ferric chloride and observation by using an optical microscope.

\subsection{Failure Time Measurement}

Observation of failure time was conducted by using Torsee's Torsion Repeated and Bending Fatigue Machine with only one level of loading $3^{\circ}$ in each test condition. The purpose of the test is to observe the ability of CuZn cast alloys to accept dynamic loads.

\subsection{Fractography Analysis}

Fractographic observations were conducted on the surface of broken fatigue specimens by using Scanning Electron
Microscope. The aim of this observations is to observe the fracture phenomena of $\mathrm{CuZn}$ cast alloys after failure time measurement.

\section{RESULTS AND DISCUSSIONS}

\subsection{Mechanical Characteristics}

The measurement wasconducted by using $50 \mathrm{~kg}$ press load with 15 seconds press time. The test was carried out 10 points on each specimen. The hardness value of as-cast $\mathrm{CuZn}$ sand casting, annealing $\mathrm{CuZn}$ sand casting, as-cast $\mathrm{CuZn}$ permanent mold casting and annealing $\mathrm{CuZn}$ permanent mold casting are shown in figure 1.

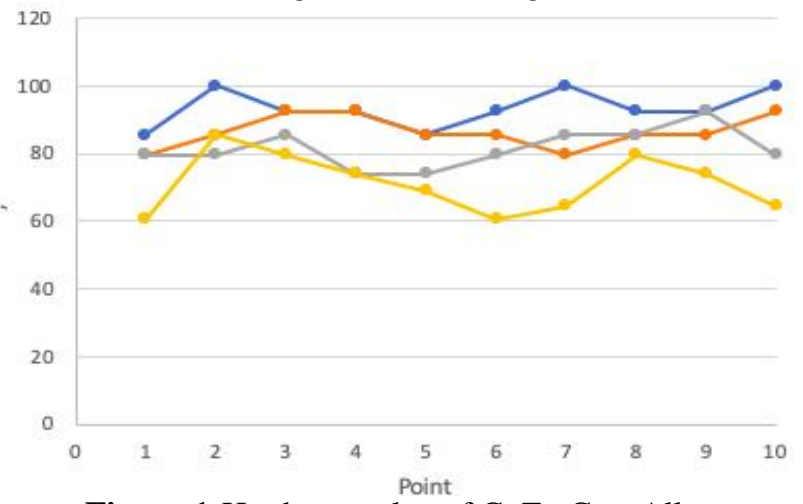

Figure 1:Hardness value of CuZn Cast Alloy

Blue indicates Hardness number of as-cast CuZn cast alloy by Permanent mold cast, Orange color shows annealed CuZn cast alloy by Permanent mold cast, Grey color shows as-cast $\mathrm{CuZn}$ cast alloy by Sand cast, and Yellow color shows annealed CuZn cast alloy by sand cast. Based on figure 1 above, the highest hardness value was produced by the CuZn cast alloy cast by permanent mold. As confirmed in the literature [10] where permanent mold castings have better strength and toughness compared to sand mold cast product because of the relatively faster cooling rate that produces a fast solidification rate which results in the fine grain structures. The lowest hardness value is owned by annealed $\mathrm{CuZn}$ sand mold cast product. The phenomenon of heat insulation that occurs on cooling process of molten metal due to the large insulating mass of sand made cooling rate works slowly [11]. Annealing process that occurs at recrystallization temperature of $400-650{ }^{\circ} \mathrm{C}$ initiates the decrease mechanical properties of CuZn cast alloy due to the increase of its plastic properties [12]. For this reason, hardness value of annealed cast product are smaller than ascast products [13-14].

Failure time measurement was conducted 10 times in each condition. Figure 2 shows the result data of Failure time measurement in accordance with the results of the hardness measurement. As-cast $\mathrm{CuZn}$ alloy permanent mold has the highest failure time value of 37500 cycles with an average of 33240 and decreased to 35600 cycles at the highest value with an average of 29380 cycles after annealing at $400{ }^{\circ} \mathrm{C}$ for 2 hours. A very significant difference was found in sand casting product which has the highest failure time only 25050 cycles with an average value of 22505 cycles. The annealing process with temperature $300{ }^{\circ} \mathrm{C}$ for 2 hours initiates reduction in the highest failure time value of the 
Nurhabibah Paramitha Eka Utami et al., International Journal of Emerging Trends in Engineering Research, 8(9), September 2020,5688 - 5692

sand casting product which is 17800 cycles with an average value of 15760 cycles. As confirmed in the literature [7], This phenomenon shows that the annealing process makes the reduction of hardness value in CuZn alloys and also makes this alloy have good machinability.

a

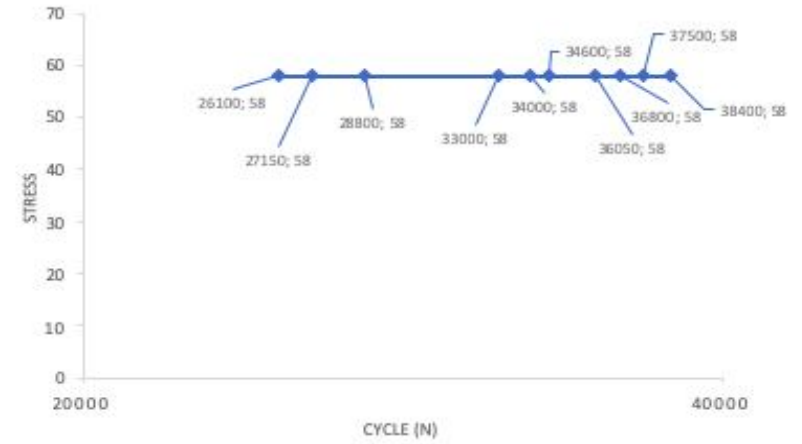

b

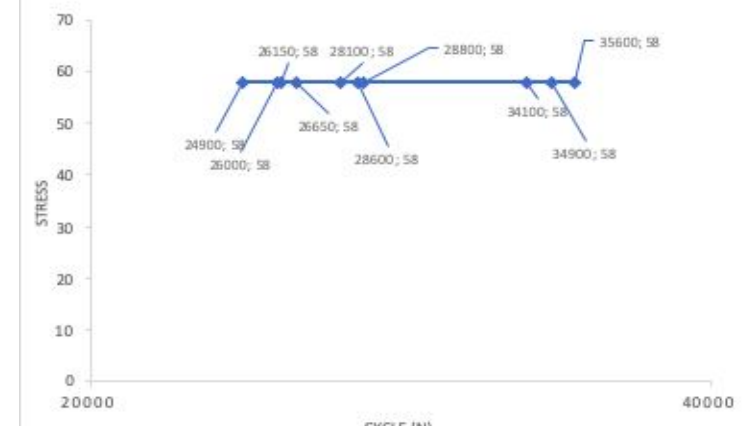

c

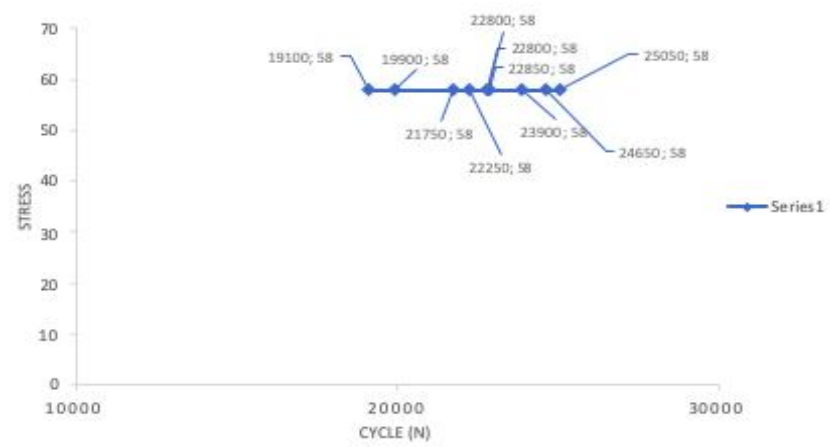

d

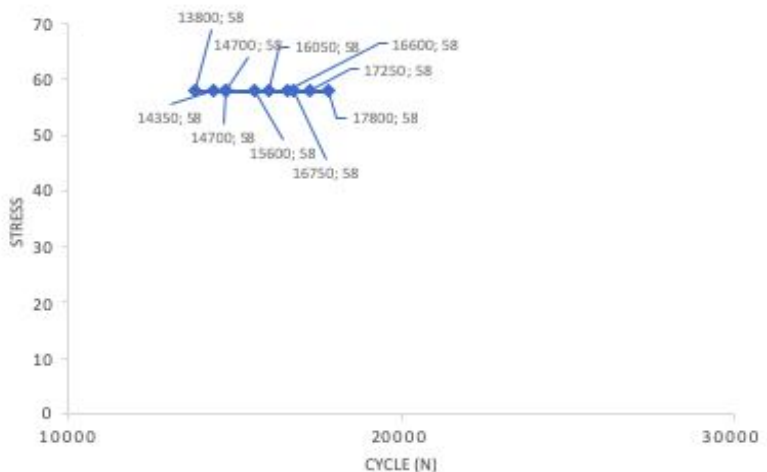

Figure 2:Failure Time Measurement of CuZn cast alloy a). As-cast Permanent mold cast b). Annealed Permanent mold cast c). As-cast Sand mold cast d). Annealed sand mold cast

\subsection{Microstructure Analysis}

Figure 3 and figure 4 show the microstructure of $\mathrm{CuZn}$ cast alloy produced using permanent molds and sand molds. Based on the data obtained, as-Cast Product by permanent mold casting has a smaller dendrite arm spacing than the same product that exposed annealing treatment. The rapid cooling rate also causes the rapid solidification process, this affects the mechanical properties in the case are the hardness value and failure time measurement that both of it have the highest value. The average Denrite arm spacing of as-Cast Product by permanent mold casting is $74.62 \mu \mathrm{m}$, it is higher than the same product that annealed at a temperature of 400 ${ }^{\circ} \mathrm{C}$ for 2 hours which is only $62.19 \mu \mathrm{m}$. the average Denrite arm spacing of as-Cast Products by sand casting is $59.97 \mu \mathrm{m}$ while the $\mathrm{CuZn}$ alloy cast by sand casting product that is annealed at $400{ }^{\circ} \mathrm{C}$ for 2 hours has the lowest average Denrite arm spacing value, $51.86 \mu \mathrm{m}$. The microstructure of $\mathrm{CuZn}$ cast alloy shows the presence of very dominant $\alpha$ phases and the minor presence of $\beta$ phase is shown in the dark zone around the grain boundary. Literature [4] shows that the presence of $\beta$ phase will be more intense as the annealing temperature increases in the $\mathrm{CuZn}$ alloy.
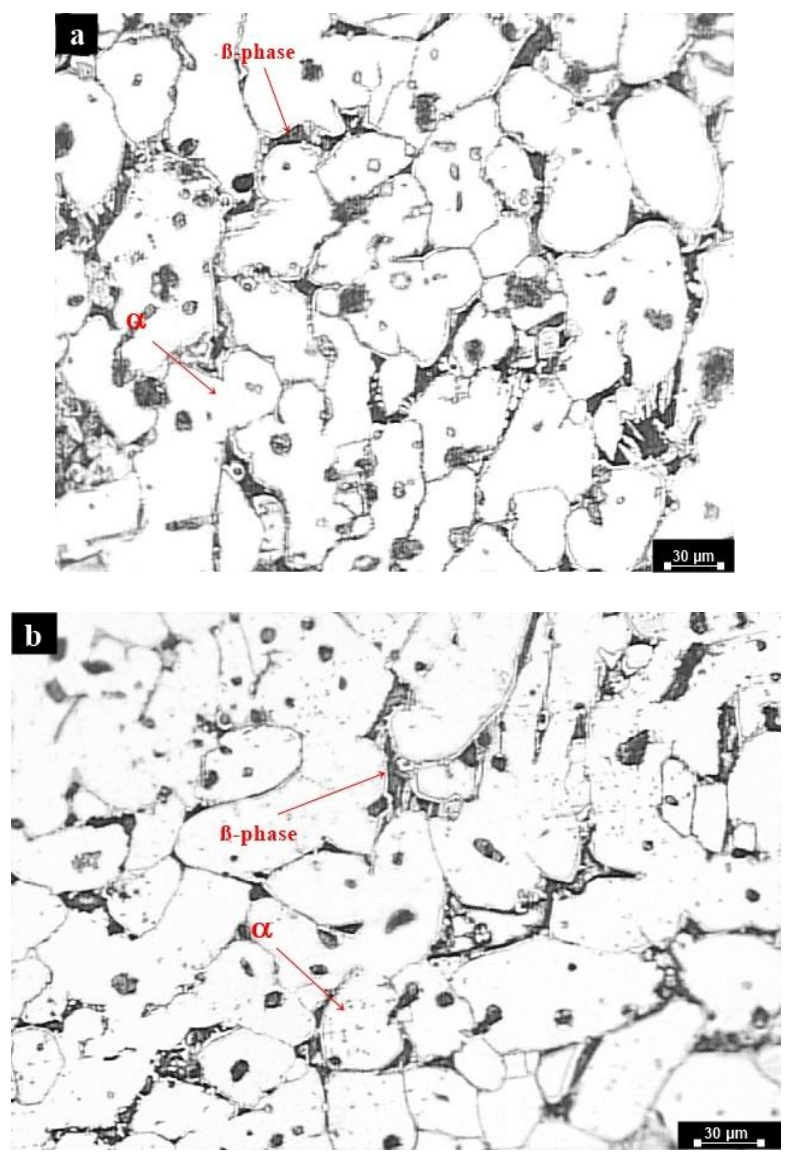

Figure 3:Microstructure of CuZn cast alloy by Permanent mold casting a). As-cast b). Annealed 

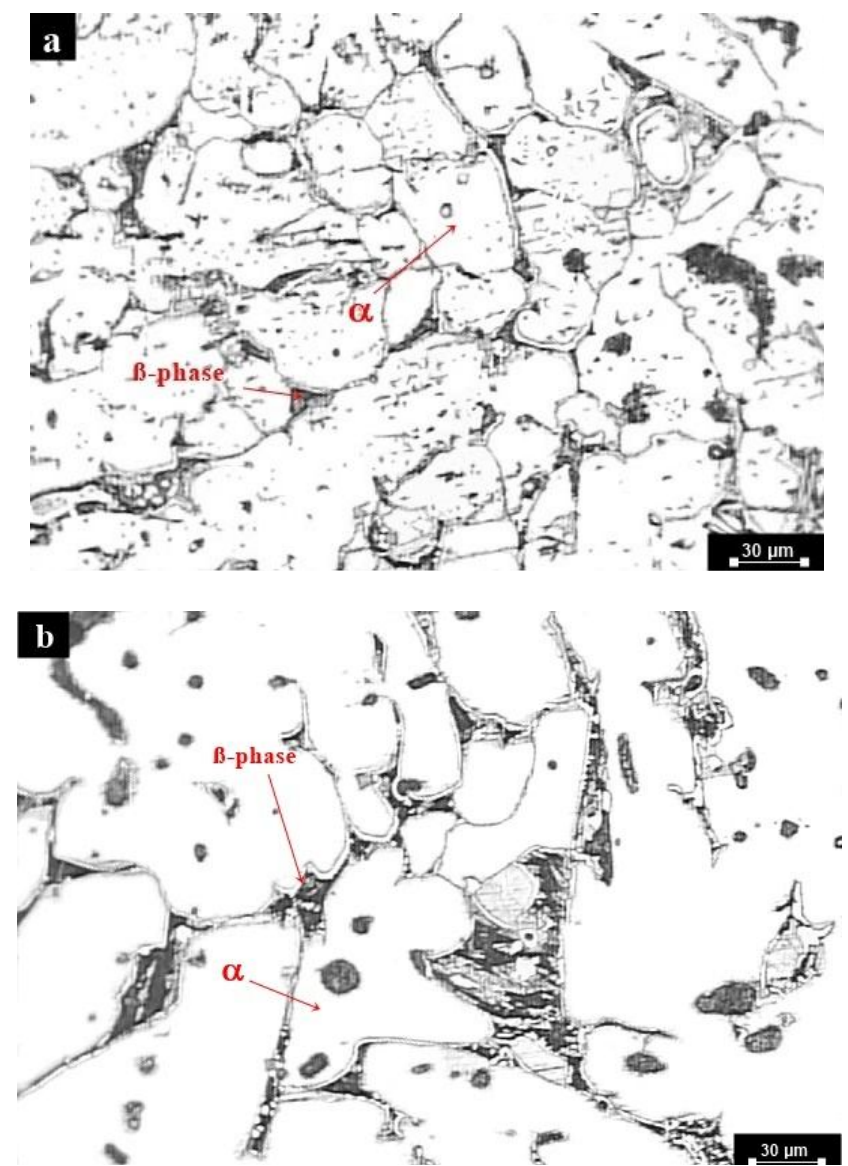

Figure 4:Microstructure of CuZn cast alloy by sand casting a). As-cast b). Annealed

\subsection{Fractography Analysis}

Fractographic measurement was conducted on the surface of the broken specimen as a result of failure time measurement. The aim of this measurement is to analyze the phenomenon of fracture specimen after fatigue testing both in as-cast and annealed conditions at $400^{\circ} \mathrm{C}$ for 2 hours. Fractographic observation was carried out by using Scanning electron microscope with 50x and 200x magnification in each specimen. The results of the fractographic observations are shown in figures 5 to 8 .

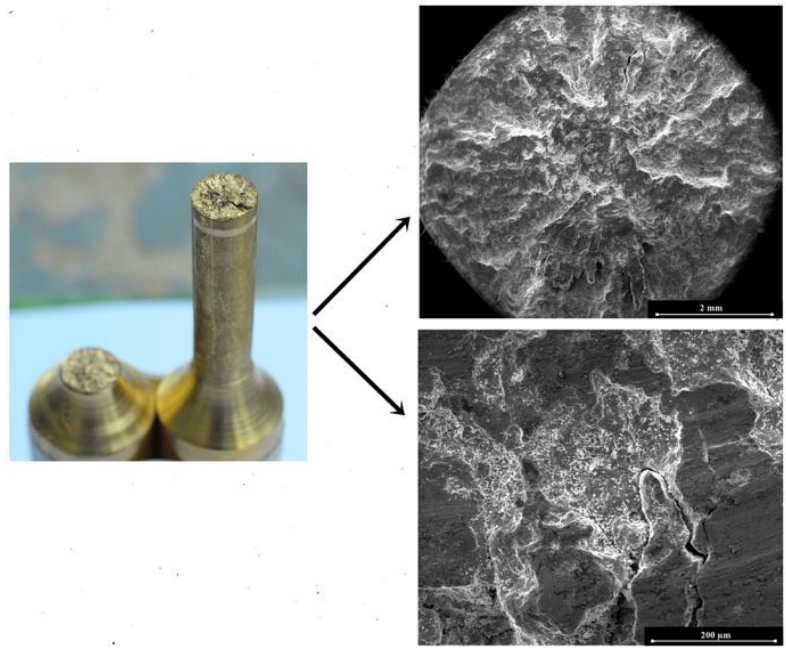

Figure 5:Fractography of $\mathrm{CuZn}$ cast alloy by Permanent mold casting (as-cast)

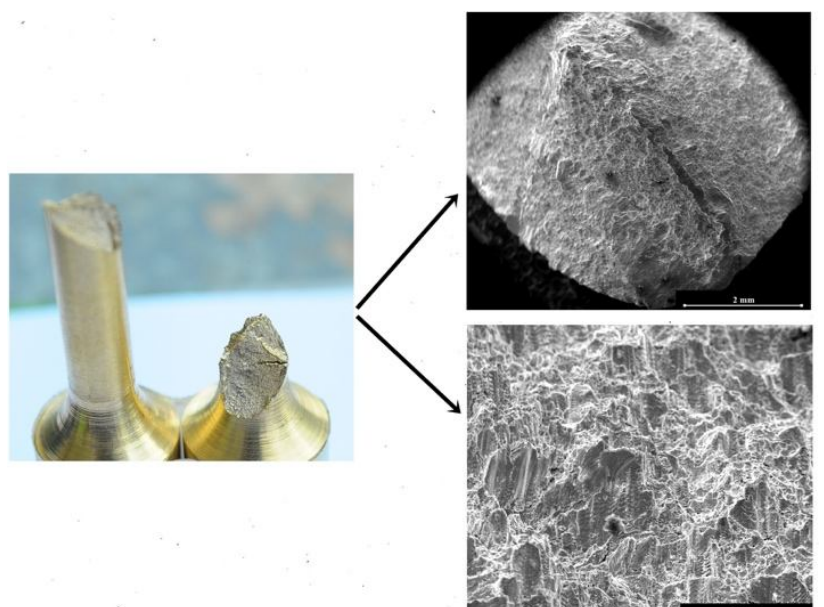

Figure 6:Fractography of CuZn cast alloy by Permanent mold casting (Annealed)

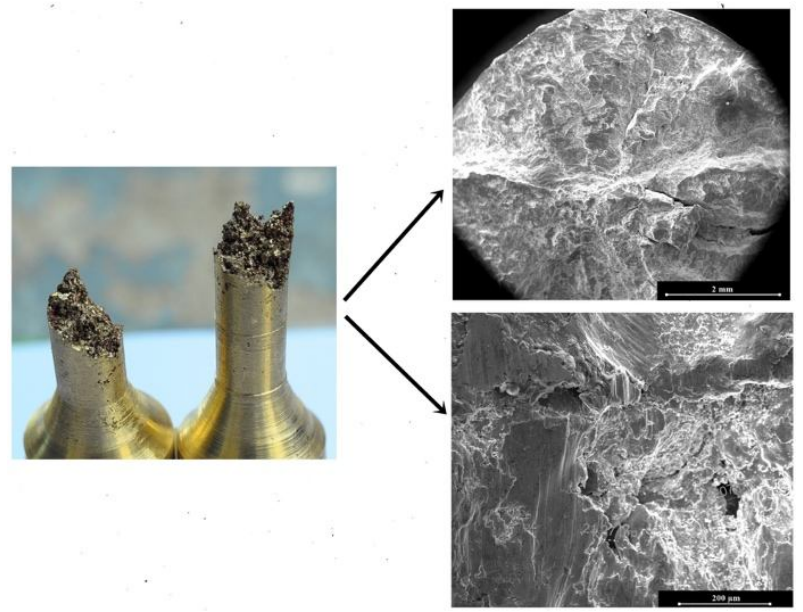

Figure 7:Fractography of $\mathrm{CuZn}$ cast alloy by Sand casting (as-cast)

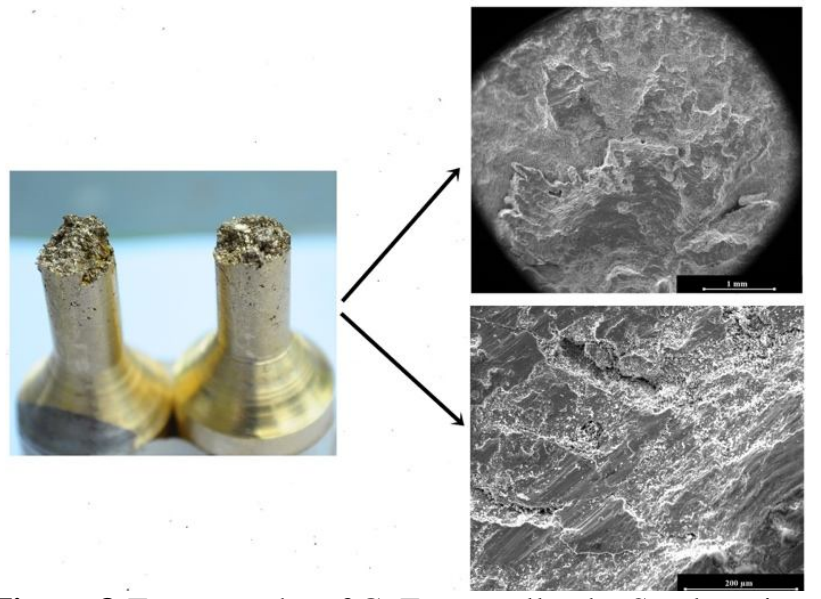

Figure 8:Fractography of CuZn cast alloy by Sand casting (annealed)

Fractography of CuZn cast alloy by Permanent mold casting (as-cast) the fracture form tends ductile, whereas in $\mathrm{CuZn}$ cast alloy by Permanent mold casting (Annealed) the fracture morphology formed $45^{\circ}$ indicating the specimen got torque loading. The visible of striation on fracture surfaces indicates the specimen receives dynamic loading. Fractography of $\mathrm{CuZn}$ cast alloy by Sand casting (as-cast) shows the fracture form tends brittle and sandy. This indicates that the specimen results of sand casting. On 
Fractography of $\mathrm{CuZn}$ cast alloy by Sand casting (annealed), the surface of fracture looks smoother than the as-cast specimen, but in this condition the striation pattern is not apparent clearly. Based on the data obtained, annealing treatment on $\mathrm{CuZn}$ initiates increasing in the ductility properties.

\section{CONCLUSIONS}

In this study, it was discovered that annealing treatment of $400{ }^{\circ} \mathrm{C}$ for 2 hours on $\mathrm{CuZn}$ cast alloy affected its mechanical properties whereas there was the reduction in hardness value and fatigue toughness of the annealed alloy . In addition, permanent mold casting is considered to have a good toughness value when compared to sand casting products.

\section{ACKNOWLEDGEMENT}

The authors would like to thank LPPM University of Sriwijaya for the financial supports (grant 0146.54/UN9/SB3.LP2M.PT/2019), and also great appreciate to Mr. Randi Pisasefsio for support and help this research.

\section{REFERENCES}

1. Achiţei, D. C., Vizureanu, P., Minciună, M. G., Cimpoeşu, N., \& Istrate, B. (2017). Improvement of structural characteristics for cuzn alloy through heat treatments. Key Engineering Materials, 750 KEM, 3-8. https://doi.org/10.4028/www.scientific.net/KEM.750.3

2. Agbo, C. O. A. (2011). Recycle Materials Potential of Imported Used Vehicles in Nigeria. Nigerian Journal of Technology, 30(3), 118-128.

3. Alo, O. (2015). Investigation of Mechanical Properties and Microstructure of Brass Alloys Obtained from Recycled Copper and Zinc Metals. International Journal of Scientific \& Engineering Research, 6(9), 799-806.

4. Ataya, S., Seleman, M. E. (2012). Microstructure Stability of CuZn37 Brass. International Materials Symposium.

5. Hisashi, I., Haruhiko, A., \& Yoshiharu, K. (2009). Mechanical Properties and Machinability of Extruded Cu-40 \% Zn Brass Alloys with Bismuth via Powder Metallurgy Process $\uparrow$. Ransactions of JWRI, 38(1).

6. Igelegbai, E. E., Alo, O. A., Adeodu, A. O., \& Daniyan, I. A. (2017). Evaluation of Mechanical and Microstructural Properties of Brass Alloy Produced from Scrap Copper and Zinc Metal through Sand Casting Process. Journal of Minerals and Materials Characterization and Engineering, 05(01), 18-28. https://doi.org/10.4236/jmmce.2017.51002

7. Jha, S. K., Balakumar, D., \& Paluchamy, R. (2015). Experimental analysis of microstructure and mechanical properties of copper and brass based alloys. International Journal of Automotive and Mechanical Engineering, 11(1), 2317-2331. https://doi.org/10.15282/ijame.11.2015.14.0195
8. Omotoyinbo, J. A., \& Aribo, S. (2009). Effect of Stress Relief Annealing and Homogenizing Annealing on the Microstructure and Mechanical Properties of Cast Brass. The Pacific Journal of Science and Technology, 10(1), 15-19.

9. Ozgowicz, W., Kalinowska-Ozgowicz, E., \& Grzegorczyk, B. (2010). The microstructure and mechanical properties of the alloy $\mathrm{CuZn30}$ after recrystallizion annealing. J.Amme, 40(1), 15-24.

10. Prasad, D., \& Ratna, S. (2018). Decision support systems in the metal casting industry: An academic review of research articles. Materials Today: Proceedings, 5(1), 1298-1312. https://doi.org/10.1016/j.matpr.2017.11.215

11. Production and casting of aerospace metals. (2012). Introduction to Aerospace Materials, 128-153. https://doi.org/10.1533/9780857095152.128

12. Singha. K. S. (2015). Analysis and Optimization of Sand Casting Defects With the Help of Artificial Neural Network. International Journal of Research in Engineering and Technology, 04(05), 24-29. https://doi.org/10.15623/ijret.2015.0405005

13. A. D. Anggono, N. Ernawan, and T. W. B. Riyadi, "Analysis of mechanical and metallographic properties on the joining between aluminum and brass by using the brazing method," Int. J. Emerg. Trends Eng. Res., vol. 8, no. 2, pp. 440-446, 2020.

14. E. Julianto, W. A. Siswanto, and M. Effendy, "Characteristics of Temperature changes and Stress of Float Glass," Int. J. Emerg. Trends Eng. Res., vol. 7, no. 9, pp. 228-233, 2019. 